\title{
Antonio Cortijo Ocaña. Sor Juana Inés de la Cruz o la búsqueda de identidad. Sevilla: Renacimiento, 2015.
}

Sumidos ya sin remedio en la "edad de la información", quienes se dedican al rastreo y manejo de fuentes documentales se saben sobrepasados de antemano. La incomodidad de la sobreabundancia textual, sin embargo, no es exclusiva de nuestra época. El vértigo de la infinitud, bien representado en las bibliotecas borgeanas y las posibilidades combinatorias sugeridas por Lulio, aparece de tanto en tanto, casi como una versión distópica del maná. Algunos expresan su renuncia limitándose al canon; otros, derrotados por la empresa, manejan el exceso renunciando a cualquier consulta, $\mathrm{o}$ se adentran en la espesura para no volver. Un último grupo, al que pertenecen sor Juana Inés de la Cruz y Antonio Cortijo, desmonta los libros para construir otros, gesto epistemológico casi divino para quien trata de imponer el logos sobre el caos. Es, en definitiva, la casa que habitan los humanistas.

Sor Juana Inés de la Cruz o la búsqueda de identidad nos ofrece claves para entender la fábrica de este edificio. No lo hace reiterando lo ya sabido, lo que contribuiría a su vez a la montaña de opiniones y especulaciones largamente sabidas, sino presentando los criterios de selección que apuntalan la más moderna literatura novohispana en las fuentes europeas. Antonio Cortijo, cuya formación en letras clásicas le permite considerar la obra de sor Juana desde una perspectiva vedada a muchos, ha desarbolado, tal vez sin saberlo, la nave barroca de la poeta americana. En este libro tampoco encontraremos un análisis de las prácticas finiseculares que entendemos como "barrocas" o, al menos, no uno al uso. En su lugar, la filología abre espacios de significado aplicando el microscopio, el catalejo y la aguja de marear, instrumentos para reconsiderar la obra de sor Juana, quien tanto insistió en el "bien mirado" y a quien tanto le gustaban los artefactos. El autor evita abordar prácticas feministas, perderse en el espectáculo barroco, en los debates sobre la legitimación teológica o en la construcción del nuevo sujeto americano. Son temas que no relega como parte de su análisis, pero que deja sujetos a las ideas centrales de transferencia, trasvase, desmontaje y construcción que sor Juana, cual computadora humana, practica como sistema literario.

Es un alivio prescindir de largas notas eruditas que ahogarían el análisis y disponer, en cambio, de una serie de textos clásicos que tocan directamente la obra de sor Juana (incluyendo tres apéndices documentales tangenciales). Particularmente en el segundo capítulo (el más extenso entre alguno sumamente breve), el lector puede hacer el ejercicio propuesto: leer un villancico y, consecutivamente, las fuentes en su versión bilingüe, traducidas por el autor 
en la mayor parte de los casos. De ese modo es posible trazar los parámetros de selección utilizados por sor Juana para construir, a partir de versos de Virgilio y textos patrísticos y bíblicos, una Virgen heroica. Los centones, esos libros que llegaron a ser delirantes en su propia lógica del caos, se despliegan ahora como destilaciones calibradas, modeladas en la técnica de otras mujeres eruditas como Faltonia Proba, según detalla Antonio Cortijo en su primer capítulo. Sor Juana, argumenta, es el último eslabón de la cadena, seleccionando, reduciendo y mejorando la herencia cultural a la que rinde tributo. La idea de una construcción mariana dominante a partir de fuentes paganas y cristianas no es, evidentemente, original. Sí lo es la forma de exponer los nudos del tapiz, pero también de llamar la atención sobre detalles menos aparentes: desde la traslación del ritmo (de carmen a canto) y la combinación exacta de fuentes, hasta usos léxicos no documentados como "peregrina” (¿probablemente un simple gongorismo "a lo divino"?).

Los capítulos dedicados al Neptuno alegórico ofrecen más indicios de cómo la información se ensambla para construir armazones, en este caso geopolíticos. En ellos, la nueva y vieja Espańa (centro y periferia) alojan sujetos trasplantados en ambas orillas en continuidad, no sólo geográfica, sino genética. La alegoría no es una figura casual, como tampoco lo son las dicotomías expuestas por el jeroglífico (paz/guerra; fuerza/comercio; armas/letras). Más interesante es la reiterada presencia de Virgilio, que ahora sirve para consolidar la idea de lo femenino intelectual; de la identidad novohispana capaz de prescindir de Espańa; y del arco como libro abierto al buen gobernante capaz de leerlo, sustituto barroco del espejo de príncipes humanístico y espectáculo público con lecturas múltiples que incluyen la crítica contemporánea. Para el profesor Cortijo el evemerismo, al que dedica un capítulo centrado en los códigos, es la llave para descifrar los enigmas antiguos, prefiguraciones de cuyo revestimiento deben ser despojados para revelar verdades universales. Todos pensamos, claro está, en Atanasio Kircher, sincrético donde los haya, como modelo de trazar correspondencias, incluyendo sus felices y creativos errores. Menos presente es la filiación de Baltasar de Vitoria y sus acólitos herméticos, localizados en ramas superiores e inferiores del árbol como parte de una, si se quiere, secta letrada dentro de los literati, virtualmente reunida. A ella se suma sor Juana mediante este rito de pasaje, tirando líneas y más líneas de relación entre lo antiguo y lo moderno, lo simbólico y lo literal, los jeroglíficos y los emblemas, lo fingido y lo real por descifrar, uniendo todos los alfabetos como partes polivalentes de un metasistema cultural que revive el arte combinatoria contemporáneo a Leibniz.

Sor Juana Inés de la Cruz o la búsqueda de identidad concluye con un par de capítulos breves. El primero está dedicado a estudiar la actitud vital de sor Juana, emparejándola con algunas de sus acólitas y modelos femeninos 
disponibles, desde las actitudes más beligerantes a las manifestaciones más mesuradas de la fuerza, el intelecto, la voluntad y el amor. Este penúltimo apartado sirve de puente (o, más bien, de hiato reubicable) que prolonga la lectura política y criptográfica del Neptuno alegórico en el Primero sueño, los autos sacramentales y las loas. Antonio Cortijo propone, no sin lógica, que la fábrica intelectual es común a todas estas obras independientemente de su género, y que todas exploran el proceso de comprensión, es decir, son epistemológicas por encima de todo. Es todo cuanto puede hacer la inteligencia femenina de una monja americana. Es todo cuanto puede hacer cualquier mente pensante: reconstruir la ficción del intelecto en una gesta infinita robada a la post-post modernidad.

Elena del Río Parra

Georgia State University rio@gsu.edu 